\title{
Development of Utility Function for Life Insurance Buyers in the Indian Market
}

\author{
Goutam Dutta \\ Sankarshan Basu \\ Jose John
}

W.P. No.2008-12-05

December 2008

The main objective of the working paper series of the IIMA is to help faculty members, research staff and doctoral students to speedily share their research findings with professional colleagues and test their research findings at the pre-publication stage. IIMA is committed to maintain academic freedom. The opinion(s), view(s) and conclusion(s) expressed in the working paper are those of the authors and not that of IIMA.

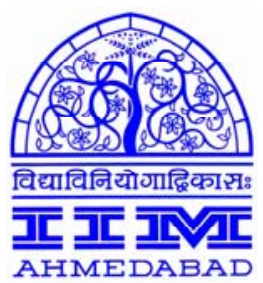

INDIAN INSTITUTE OF MANAGEMENT

AHMEDABAD-380 015

INDIA 


\title{
Development of Utility Function for Life Insurance Buyers in the Indian Market
}

\author{
Goutam Dutta ${ }^{1}$ \\ Indian Institute of Management, Ahmedabad \\ goutam@,iimahd.ernet.in \\ Sankarshan Basu \\ Indian Institute of Management, Bangalore \\ Jose John \\ Indian Institute of Management, Ahmedabad
}

\begin{abstract}
Insurance as a financial instrument has been used for a long time. The dramatic increase in competition within the insurance sector (in terms of providers coupled with awareness for the need for insurance) has concomitantly resulted in more policy options being available in the market. The insurance seller needs to know the buyer's preference for an insurance product accurately. Based on such multi-criterion decision-making, we use a logarithmic goal programming method to develop a linear utility model. The model is then used to develop a ready reckoner for policies that will aid investors in comparing them across various attributes.
\end{abstract}

Keywords: Finance, Mathematical Programming, Utility Theory

(This paper is currently in review in Journal of Operational Research Society, UK)

(C) Copyright Goutam Dutta \& Indian Institute of Management, Ahmedabad and Sankarshan Basu of Indian Institute of Management, Bangalore. Please do not quote without Author's permission

${ }^{1}$ Corresponding author 


\section{Introduction}

The liberalization of the Indian insurance sector has resulted in a number of insurance companies entering the market. This has led to a plethora of choices both in terms of service providers as well as products to the consumers. With the huge untapped market that still exists, the insurance market in India is expected to increase rapidly. In this paper we attempt to develop a ready reckoner to match the buyer's requirement with the products that the insurance companies are offering. This will aid policyholders and potential investors in comparing the various policies being offered.

In brief, we attempt to find

a) the attributes of the product that a policy holder is looking for,

b) given these attributes, the relative weights of various attributes,

c) a way to compare the existing insurance products based on the framework developed, and

d) probabilities of selecting a product from a set of mutually exclusive alternatives.

Based on a Multi Criterion Decision-making Approach (MCDA) and a Logarithmic Goal Programming Method (LGPM), we develop a linear utility model to answer the above questions. While a lot of work has been done on the use of various mathematical techniques to develop utility functions, not much work has been done towards developing a utility model for insurance products. Hence, the development of a utility function is very important in the Indian context. This paper is also possibly one of the first attempts to develop a utility model of insurance products using LGPM. We believe this work will help the buyer of an insurance product to compare the existing products thereby making a better-informed buying decision.

This paper is organized as follows. Section 2 discusses the overview of the insurance market in India and the increasing importance it is garnering in that context. Section 3 outlines a literature survey on the subject. In section 4, we describe the proposed model. In section 5, we describe the logarithmic goal programming model. In section 6 , we outline the methodology followed to implement the model and arrive at the results. In this section, we also show the results obtained using a sample data set and then extend it to the larger case. Section 7 talks about the findings from the models and explanation of the output. Finally, section 8 concludes the paper as well as outlines the possible extensions that could possibly arise from the work discussed in this paper. 


\section{Overview of the Insurance Market in India}

The Indian insurance business (Overview of Insurance Sector, 2007) is currently of the order of USD10 billion (approximately INR 450 billion) and is experiencing an annual growth of about 15\% $20 \%$. In the Indian context, there are two important indicators:

1. Huge amounts of funds are available with the largest life insurer in India, the Life Insurance Corporation (LIC) of India Limited. It is interesting to note that even after about 10 years of a decontrolled insurance sector, LIC still controls over $90 \%$ of the life insurance business in India.

2. The other important indicator is the amount of premium collection for insurance policies. At present, this is about $2 \%$ of the GDP of India.

Table 1 provides a comparative analysis of per capita insurance in US, UK, Japan and India. The comparison also indicates the tremendous growth potential for insurance products in India.

Table 1: Comparison of per capita Insurance

\begin{tabular}{|c|c|}
\hline Country & Life Premium Per Capita US \$ in 2005 \\
\hline Japan & 2956.3 \\
\hline UK & 3287.1 \\
\hline USA & 1753.2 \\
\hline India & 10 \\
\hline
\end{tabular}

With the advent of private players, there has been an increase in the number of new and innovative products.

\section{Literature Survey}

There is a considerable volume of literature on various products in insurance as well as the use of various optimization techniques in insurance policies. In fact, optimization techniques have in some way always formed the backbone of the insurance policy selection by customers - it is like any portfolio selection problem. In that sense, even the seminal work of Markowitz (1952) on portfolio theory can be extended and applied to the insurance domain. However, not much work has been done, in particular, using LGPM in the life insurance industry. But some parallels can be drawn from similar 
(not identical) work that has been done in the banking sphere, especially in the Asset Liability Management (ALM) sphere (Bessis (2002)).

In terms of the insurance domain, Basu et al. (2004) discuss the use of different operational research and management science models in various insurance applications. Das and Basu (2003) also have used an optimization technique to obtain the optimal premium in the case of automobile insurance in the presence of non-claims bonus schemes. Das (2003) has also used a similar approach to look at joint life insurance polices with differential benefits and premiums to policyholders.

The Analytic Hierarchy Process (AHP), developed by Satty (1980) and Aczel and Satty (1983) provides a method of obtaining the relative criticality weighting of child indicators and relative criticality weighting of evaluators. Further, the LGPM method has been developed by Bryson and Joseph (1999). Both the AHP and the LGPM methodologies are used extensively in this work.

Another approach to looking at these types of problems is the use of "Conjoint Analysis". Conjoint Analysis is primarily a survey based research tool used in marketing sciences to measure the customer preferences among several multi - attribute products or services and then use these preferences in the pricing and servicing of the product. A lot of work on Conjoint Analysis has been done by a number of researchers - prominent amongst them are Srinivasan (1980, 1998), Srinivasan and Green (1978, 1990) and Srinivasan, Jain and Malhotra (1983). At this point we mention that according to Srinivasan and Green (1978) the conjoint methodology is based on a decompositional approach, in which the respondents react to a set of total profile descriptions. It is the job of the market researcher to find the worth of a set of individual attributes given some type of compositional rule, that are more consistent with the respondents' overall preference. On the contrary, the LGPM is a compositional and build up approach in which total utility for some multi attribute product (or service in this case) is found to be a weighted sum of the products (or services) perceived and associated value ratings. Moreover it is important to point out that a key distinction between these approaches lies in the predominant purpose for which it is used. Conjoint Analysis generally emphasizes predictive validity and regards explanation as the desirable (but secondary) objective, while the LGPM that we are discussing in this paper is true for an expectancy value theorist.

In this paper, we use the AHP and LGPM based methodology over the Conjoint Analysis methodology. The reasons for the use of the AHP and LGPM based methodology are due to the fact that no such usage has been seen in the context of insurance products and that this method also allows for an alternate approach to be used for obtaining customer preferences and then using them for further analysis. 


\section{The Model}

In order to enable a customer to choose the right insurance plan/policy, we decided to use the linear utility value concept. The utility function $\mathrm{U}(\mathrm{X})$ is defined as follows:

$$
U(X)=\sum_{i} w_{i} x_{i}
$$

where,

$$
\begin{aligned}
& \mathrm{x}_{\mathrm{i}}=\text { level of parameters/criteria } \mathrm{i} \text { important for policy selection } \\
& \mathrm{W}_{\mathrm{i}}=\text { the relative importance (weights) assigned to the } \mathrm{i}^{\text {th }} \text { criteria. }
\end{aligned}
$$

In this paper, we describe a method of finding the weights $\left(\mathrm{w}_{\mathrm{i}}\right)$ by LGPM. The methodology followed includes the LGPM method developed by Bryson and Joseph (1999) and AHP methodology developed by Satty (1980) and Aczel and Satty (1983).

We first follow the steps detailed in the AHP methodology - the steps are as follows:

1. Establish the Hierarchical Structure by interviewing experts, conducting surveys and analyzing the elements that might affect the survey results. The elements of similar importance are collected on the same level in this step.

2. The calculation of the weight of different attributes is obtained through the following four steps:

a. The attributes comparison is conducted in this step in a pair-wise manner. The scale used in this comparison is shown in Appendix.

Table 2: Basis for comparative importance

\begin{tabular}{|c|c|l|}
\hline $\begin{array}{c}\text { Comparative } \\
\text { Importance }\end{array}$ & Definition & \multicolumn{1}{c|}{ Explanation } \\
\hline 1 & $\begin{array}{c}\text { Equally } \\
\text { important }\end{array}$ & $\begin{array}{l}\text { Two decision elements (e.g., indicators) equally influence the parent } \\
\text { decision element. }\end{array}$ \\
\hline 3 & $\begin{array}{c}\text { Moderately } \\
\text { more important }\end{array}$ & One decision element is moderately more influential than the other. \\
\hline 5 & $\begin{array}{c}\text { Strongly more } \\
\text { important }\end{array}$ & One decision element has a stronger influence than the other. \\
\hline 7 & $\begin{array}{c}\text { Very strongly } \\
\text { more important }\end{array}$ & One decision element has significantly more influence over the other. \\
\hline
\end{tabular}




\begin{tabular}{|c|c|l|}
\hline 9 & $\begin{array}{c}\text { Extremely more } \\
\text { important }\end{array}$ & $\begin{array}{l}\text { The difference between influences of the two decision elements is } \\
\text { extremely significant. }\end{array}$ \\
\hline $2,4,6,8$ & $\begin{array}{c}\text { Intermediate } \\
\text { judgment values }\end{array}$ & $\begin{array}{l}\text { Judgment values between equally, moderately, strongly, very strongly, } \\
\text { and extremely. }\end{array}$ \\
\hline Reciprocals & & $\begin{array}{l}\text { If } \mathrm{v} \text { is the judgment value when } \mathrm{i} \text { is compared to } \mathrm{j}, \text { then } 1 / \mathrm{v} \text { is the } \\
\text { judgment value when } \mathrm{j} \text { is compared to } \mathrm{i} .\end{array}$ \\
\hline
\end{tabular}

b. The priority vector is calculated by dividing each comparison value by the sum of the values in corresponding fields for the aggregation of the rows; namely, the sum of the proportion each comparison value occupies in its corresponding row.

$$
\sum_{I} \text { cellvalue }_{I} / \text { column }_{-} \text {sum }_{I}
$$

Equation (2) shows the sum of the percentage each comparison value occupies in its corresponding row. An n x 1 matrix is acquired in this step.

c. The Maximum Eigenvalue is computed by multiplying the entire matrix with the acquired priority vector to produce a $\mathrm{n} \times 1$ matrix and then dividing this matrix by the priority vector to acquire unit vectors. The average of the unit vectors is sequentially calculated to acquire the maximum eigenvalue.

d. We examine for consistency because during the pair-wise comparison, discrepancies might occur between the results of the comparison and the decision. In AHP, before computing the weights based on pairwise judgments, the degree of inconsistency is measured by the Inconsistency Index (II). Perfect consistency implies a value of zero for II. However, perfect consistency cannot be demanded since, as human beings, we are often biased and inconsistent in our subjective judgments. Therefore, it is considered acceptable if II $\leq 0.1$. For II values greater than 0.1 , the pairwise judgments may be revised before the weights are computed.

Now we try to implement the LGPM methodology developed by Bryson and Joseph (1999) to ascertain the weights of the criteria in the final model. We start with a set of criteria that we think are critical in the decision-making of a customer. We attempt to find the weights ( $\mathrm{w}_{\mathrm{i}}$ 's) that different decision-makers ascribe to the different criteria through a survey. 


\section{Logarithmic Goal Programming Model}

In goal programming we minimize under achievement and over achievement from the required goal. In conventional goal programming we have these variables (under achievement and over achievement) in linear forms. In LGPM, we take the product of under achievement and over achievement and take their logarithms. The basic idea as suggested by Bryson and Joseph (1999) is that minimizing a function with two variables (linear in the objective function and summed over indices), is similar to minimizing logarithms of the product of the variables (product computed over the same indices).

We first define the sets, indices and parameters of the model

$\mathrm{I}=$ set of first criterion $\mathrm{I}=(1,2,3, \mathrm{i} \ldots . . \mathrm{Imax})$ indexed by $\mathrm{i}$

$\mathrm{J}=$ set of second criterion $\mathrm{J}=(1,2,3$......Jmax $)$ indexed by $\mathrm{j}$

$\mathrm{L}=$ Link or pair of criteria (i,j) where $i \in I$ and $j \in J j \neq i$

$\mathrm{T}=$ set of decision makers indexed by $\mathrm{t}, \mathrm{T}=(1,2, \ldots \mathrm{t} \ldots \mathrm{Tmax})$

$\mathrm{a}_{\mathrm{ij}}^{\mathrm{t}}=$ the ratio of the response to the $\mathrm{i}^{\text {th }}$ attribute with respect to the response for the $\mathrm{j}^{\text {th }}$ attribute for the $\mathrm{t}^{\text {th }}$ respondent, where $\mathrm{t} \in \mathrm{T}$ and $(\mathrm{i}, \mathrm{j}) \in \mathrm{L}$

$\mathrm{p}_{\mathrm{ij}}^{\mathrm{t}}=$ the value generated by the methodology used in this work for a given respondent $\mathrm{t}$ for the pair (i,j) where $t \in T$ and $(i, j) \in L$. The computation of the value of $\mathrm{p}_{\mathrm{ij}}^{\mathrm{t}}$ is explained in equation 3 given later.

$\mathrm{q}_{\mathrm{ij}}^{\mathrm{t}}=\mathrm{a}$ value generated by the methodology used in this work for a given respondent $\mathrm{t}$ for the pair

(i,j) where $t \in T$ and $(i, j) \in L$

$\mathrm{v}_{\mathrm{i}}$ is the decision variable of the LGPM (not normalized)

$\mathrm{w}_{\mathrm{i}}$ is the normalised decision variable or the weights of different attributes

LGPM involves a linear goal programming model in which the objective is to generate a group mean priority point vector $\mathrm{w}=\left(\mathrm{w}_{1}, \mathrm{w}_{2}, \ldots, \mathrm{w}_{\mathrm{N}}\right)$ such that for the comparison between each pair of criteria ' $\mathrm{i}$ ' and ' $\mathrm{j}$ ', the difference between the ratio $\left(\mathrm{w}_{\mathrm{i}} / \mathrm{w}_{\mathrm{j}}\right)$ and the decision-makers specified $\mathrm{a}^{\mathrm{t}}{ }_{\mathrm{ij}}$ is minimized. Please note that data value of Imax defined in this model is $\mathrm{N}$.

Let there be real numbers $\mathrm{p}_{\mathrm{ij}}^{\mathrm{t}} \geq 1, \mathrm{q}_{\mathrm{ij}}^{\mathrm{t}} \geq 1$ such that

$$
\left(\mathrm{w}_{\mathrm{i}} / \mathrm{w}_{\mathrm{j}}\right) *\left(\mathrm{p}_{\mathrm{ij}}^{\mathrm{t}} / \mathrm{q}_{\mathrm{ij}}^{\mathrm{t}}\right)=\mathrm{a}_{\mathrm{ij}}^{\mathrm{t}} \text {, }
$$

where $\mathrm{p}_{\mathrm{ij}}^{\mathrm{t}}$ and $\mathrm{q}_{\mathrm{ij}}^{\mathrm{t}}$ both cannot be greater than 1. It should be noted that if the computed value of $\mathrm{p}_{\mathrm{ij}}^{\mathrm{t}}<$ 1 , then, we replace the computed value by 1 , else we retain the computed value of $\mathrm{p}_{\mathrm{ij}}^{\mathrm{t}}$.

Then, $\mathrm{p}_{\mathrm{ij}}^{\mathrm{t}}=\mathrm{q}_{\mathrm{ij}}^{\mathrm{t}}=1$ implies that $\left(\mathrm{w}_{\mathrm{i}} / \mathrm{w}_{\mathrm{j}}\right)=\mathrm{a}_{\mathrm{ij}}^{\mathrm{t}}$, 
$\mathrm{q}_{\mathrm{ij}}^{\mathrm{t}}>1$ implies that $\left(\mathrm{w}_{\mathrm{i}} / \mathrm{w}_{\mathrm{j}}\right)>\mathrm{a}_{\mathrm{ij}}^{\mathrm{t}}$, and $\mathrm{p}_{\mathrm{ij}}^{\mathrm{t}}>$ 1implies that $\left(\mathrm{w}_{\mathrm{i}} / \mathrm{w}_{\mathrm{j}}\right)<\mathrm{a}_{\mathrm{ij}}^{\mathrm{t}}$.

Therefore, if $\mathrm{p}_{\mathrm{ij}}^{\mathrm{t}}=\mathrm{q}_{\mathrm{ij}}^{\mathrm{t}}=1$ for each pair of criteria ' $\mathrm{i}$ ' and ' $\mathrm{j}$ ', then the set of point estimates provided by the decision-maker ' $t$ ' is consistent; otherwise the data are inconsistent and our problem then is to minimize the product $\prod_{\mathrm{ieI}} \prod_{\mathrm{j} \epsilon J} \mathrm{p}_{\mathrm{ij}}^{\mathrm{t}} \mathrm{q}_{\mathrm{ijj}}^{\mathrm{t}}$.

Aczel and Satty (1983) suggested that the group 'consensus' pairwise comparison values should be the geometric mean of the individual pairwise comparison values. Rather than focusing on each pairwise comparison, we will focus on the entire set of pairwise comparison values. Therefore if $\mathrm{T}$ is the index set of the decision-makers and $\mathrm{M}=|\mathrm{T}|$, then it follows that for the group, our problem is to minimize the product for all respondents $t \in T$ and each value of $(i, j) \in L$. Thus the problem is to

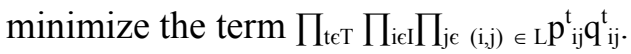

This translates to solving the following linear goal programming problem where the decision variables are the un-normalized vector $\left(\mathrm{v}_{1}, \mathrm{v}_{2}, \ldots, \mathrm{v}_{\mathrm{N}}\right)$. In this case, instead of minimizing the product, we minimize the logarithm of the product and use it in a linear programming problem.

Minimize $Z=\ln (\theta)=\left(\frac{1}{\mathrm{~K}}\right) \sum_{t} \ln \left(\Theta^{t}\right)$

subject to

$\ln \left(\mathrm{v}_{\mathrm{i}}\right)-\ln \left(\mathrm{v}_{\mathrm{j}}\right)+\ln \left(\mathrm{p}_{\mathrm{ij}}^{\mathrm{t}}\right)-\ln \left(\mathrm{q}_{\mathrm{ij}}^{\mathrm{t}}\right)=\ln \left(\mathrm{a}_{\mathrm{ij}}^{\mathrm{t}}\right) \quad \forall \mathrm{t} \in \mathrm{T} ;(\mathrm{i}, \mathrm{j}) \in \mathrm{L}$

$(5)$

$\left(\frac{1}{K}\right) \sum_{i \in I} \sum_{j \in J}\left(\left(\ln \left(p_{i j}^{t}\right)+\ln \left(q_{i j}^{t}\right)\right)-\ln \left(\Theta^{t}\right)\right)=0 \quad \forall \quad t \in T$

where $\mathrm{K}=\mathrm{N}^{*}(\mathrm{~N}-1) ; \mathrm{I}=\{1,2, \ldots . \mathrm{N}\}$ and all variables are non-negative

The optimal solution of this problem results in the un-normalized vector $v=\left(v_{1}, v_{2}, \ldots, v_{N}\right)$, which can then be normalized to give our normalized consensus priority point vector $\mathrm{w}=\left(\mathrm{w}_{1}, \mathrm{w}_{2}, \ldots, \mathrm{w}_{\mathrm{N}}\right)$ where $\left(\mathrm{v}_{\mathrm{i}} / \mathrm{v}_{\mathrm{j}}\right)=\left(\mathrm{w}_{\mathrm{i}} / \mathrm{w}_{\mathrm{j}}\right)$ for each $(\mathrm{i}, \mathrm{j})$.

Properties of the model

a) This logarithmic goal-programming model will never be infeasible

b) LGPM is mathematically similar to the minimum sum of absolute errors regression model, which is known to be resistant to the presence of outliers.

c) Hence the presence of outliers in the pair-wise comparison preference data should not have any adverse effect. 
d) Given that $\ln (\theta)$ is the objective function, $\theta$ is the minimum average value that each entry in the comparison matrix would have to be multiplied by in order to make the set of pair-wise comparison values consistent.

Thus if the decision-makers' estimates were consistent we would have $\ln (\theta)=0$ or $\theta=1$. Otherwise $\ln (\theta)>0$ or $\theta>1$.

\section{Dominance}

Dominance occurs when one option performs at least as well as another on all criteria and strictly better than the other on at least one criterion. In principle, one option might dominate all others, but in practice this is unlikely. Once the decision-maker has ranked the different insurance products on the basis of the criteria, an initial step can be to see if any of the options dominate others.

\section{Linear Additive Model}

According to a study by Cochrane and Zeleny (1973), if dominance is not observed, and it can either be proved, or reasonably assumed, that the criteria are preferentially independent of each other and if uncertainty is not formally built into the MCDA model the simple linear additive evaluation model is applicable. The linear model shows how an option's values on the many criteria can be combined into one overall value. This is done by multiplying the value score on each criterion by the weight of that criterion (determined by LGPM), and then adding all those weighted scores together. In case there are two parameters, which are not preference-independent, then one approach can be to club together the two variables and treat them as one variable. Otherwise a more complicated MCDA-based model that calculates correlation among the parameters can be used, but we will not go into that.

\section{Methodology}

In this section, we describe the data collection method employed in this study and the modeling details. Further, in sub-section 6.2, we describe the exact workings of the model using a smaller dataset and a reduced set of factors. This we hope will significantly enhance the readability of the paper. Finally, sub-section 6.3 talks about the mathematical implementation of the full scale model described in this paper.

\subsection{Data Collection}

We collected information on the life insurance policies and conducted a survey to determine the relative importance given to these factors. We first demonstrate the computational part by having a sample data set which we solve in the Excel solver (this is explained in Appendix - 1). This sample data has 10 respondents and eight attributes. In this sample study we found that there is no added advantage to having a scale of $1-100$ and hence, we reduced the choice set to 1 to 9 . The 
questionnaire is provided in Appendix-2. For the life insurance study, we had 102 respondents. However, some responses were inaccurate or had missing data points; excluding these, we were left with 87 respondents. It should be noted that the proposed method of generating priority point vectors in the literature suggests that each respondent should specify values for each pair-wise comparison. Since we had a large number of factors for each category of policy, we decided to reduce the number of values input to one for each factor. We then derived the pair wise comparison values. The survey was conducted amongst predominantly salaried or self-employed persons.

In the second part of the survey, we requested the respondents to rate the existing products available in the market. Each respondent was told to rate each product on each attribute.

\subsection{Model explanation with a sample data set}

In this section we describe the computational aspects of the model used in this paper on a sample dataset that can be easily solved in the Excel solver. The information collected was the same as in the case of the implementation of the full model; i.e. we collected information on the life insurance policies and conducted a survey to determine the relative importance given to these factors. This sample data had 10 respondents and eight attributes. In this sample study we found that there is no added advantage to having a scale of $1-100$ and hence, we reduced the choice set to 1 to 9 in the detailed study. The explanation of the computational part and the results obtained using this sample dataset which was solved using the Excel solver is provided in Appendix 1.

\subsection{Implementation of the Mathematical Model}

We applied the LGPM to a linear model with nine attributes. The decision variables were the weights of different variables. We obtained the weights of nine attributes from LGPM using our dataset of 87 respondents. The number of variables for the mathematical programming model is over 7200 . While a small dataset can be implemented in the popular solver in Excel (as has been demonstrated in the example highlighted in Appendix 2), it is difficult to implement a large mathematical programming problem in Excel Solver. Therefore we choose The AMPL (A Mathematical Programming Language) developed by Fourer et al. (1993) and CPLEX solver (Version 8.0) for implementing the LGPM. The solution time for this model is less than one minute. The other advantages of using AMPL are as follows:

a) The model in the computer code can be written in the same way as the formulation is written.

b) Model data independence. 

c) Model solver independence.
d) There is no restriction on the number of variables.

We grouped the data suitably to identify if respondents in different salaried classes had allotted different weights.

\section{Model Findings}

We evaluated the existing life insurance policies using the weights. Specifically, we looked at moneyback life insurance policies (where maturity benefits are paid in installments at fixed intervals).

Key parameters for Life Insurance Policies

1. Low premium

2. Flexibility in payment structure

3. Tax benefits in insurance plan

4. Benefits on death

5. Benefits on survival

6. Good customer service

Online payment

Renegotiation of term/insured amount

7. Bonus

8. Add-ons, Special Schemes

Loan against policy

Group schemes

9. Availability of riders enabling customization of insurance plan

Accident and disability benefit

Critical illness benefit

The LGPM model yielded the following weights provided in Table 3. While we found the equations for different income classes, we found that the variations of the values of weights were not more than $2 \%$. 
Table 3: Weights assigned from the model

\begin{tabular}{|l|c|}
\hline \multicolumn{1}{|c|}{ Attribute Name (indexed by i) } & Weight $\left(\mathbf{a}_{\mathbf{i}} \mathbf{)}\right.$ \\
\hline Low Premium & 0.1141 \\
\hline Flexibility in payment structure & 0.1059 \\
\hline Tax benefits in insurance plan & 0.1362 \\
\hline Benefits on death & 0.1319 \\
\hline Benefits on survival & 0.1211 \\
\hline $\begin{array}{l}\text { Good Customer Service } \\
\text { - Online Payment }\end{array}$ & 0.1014 \\
\hline Bonus & 0.0978 \\
\hline $\begin{array}{l}\text { Add-ons, Special Schemes } \\
\text { - Loan against Policy }\end{array}$ & 0.0856 \\
\hline $\begin{array}{l}\text { Availability of Riders enabling customization of insurance plan } \\
\text { - Accident and disability benefit } \\
\text { - Critical illness benefit } \\
\text { - Major surgical assistance }\end{array}$ & \\
\hline
\end{tabular}

Based on this, we find that the income tax benefit is the most important criterion for insurance. The benefit on death is the second important criterion for an insurance buyer. Again, looking at the coefficients, we can also say that add on, special schemes are the least important criterion. The life insurance study data was also categorized by Salary Class and studied. However, the weights were found to be largely similar, and within \pm 0.02 of the values shown above. However, there was significant difference in the consistency indicators for each class of salary, as shown in the table below. Therefore, it is appropriate to use the aggregate figure and not specific weights for each salary class.

Table 4: Respondent's Profile and Consistency Indicators

\begin{tabular}{|l|c|c|}
\hline \multicolumn{1}{|c|}{ Salary per month } & Number of Responses & Consistency Indicator \\
\hline Less than Rs. 10,000 & 8 & 0.5578 \\
\hline Rs. $10,000-$ Rs. 20,000 & 30 & 0.7690 \\
\hline Rs. $20,000-$ Rs. 30,000 & 30 & 0.7460 \\
\hline Rs. $30,000-$ Rs. 40,000 & 8 & 0.7795 \\
\hline Rs. $40,000-$ Rs. 50,000 & 7 & 0.4962 \\
\hline More than Rs. 10,000 & 4 & 0.7350 \\
\hline Aggregate & $\mathbf{8 7}$ & \\
\hline
\end{tabular}

We note that certain salary classes (extremes) had very few respondents. Therefore, the validity of results for such classes is suspect. However, one may infer that these extreme categories have 
different weights. Therefore, a more targeted survey may be required to determine weights applicable to the extreme salary classes.

\section{Evaluation of Life Insurance Policies}

Table 5: Description and Abbreviation of the Parameter

\begin{tabular}{|c|l|}
\hline Abbreviation & \multicolumn{1}{c|}{ Description of the Parameter } \\
\hline LP & Low Premium \\
\hline FPS & Flexibility in payment structure \\
\hline TB & Tax benefits \\
\hline BoD & Benefits on death \\
\hline BoS & Benefits on survival \\
\hline GCS & $\begin{array}{l}\text { Good Customer Service } \\
\text { Online Payment } \\
\text { Renegotiation of term/insured amount }\end{array}$ \\
\hline BN & Bonus \\
\hline SS & $\begin{array}{l}\text { Add-ons, Special Schemes } \\
\text { Loan against Policy } \\
\text { Group Schemes }\end{array}$ \\
\hline RID & $\begin{array}{l}\text { Availability of Riders enabling customization of insurance plan } \\
\text { Accident and disability benefit } \\
\text { Critical illness benefit } \\
\text { Major surgical assistance }\end{array}$ \\
\hline
\end{tabular}

From the above study we find that the utility of the insurance product can be expressed as

$\mathrm{U}(\mathrm{P})=0.1141 \mathrm{LP}+0.1059 \mathrm{FPS}+0.1362 \mathrm{~TB}+0.1319 \mathrm{BOD}+0.1211 \mathrm{BCS}+0.1014 \mathrm{GCS}+0.0978$

$\mathrm{BN}+0.0856 \mathrm{SS}+0.1059 \mathrm{RID}$

The existing six products have been compared on all the nine attributes and their rating is given in Table 6 . We also show the utility of the existing products. This will help both - the consumer and the insurance providers.

This will also help the buyer in deciding the premium for a product; particularly since the buyer is interested in finding how much premium he/she should pay for this product. From this study it is possible to conclude that the buyer would be willing to pay a higher premium for product P1 (whose utility value is 4.07 ) as compared to product $\mathrm{P} 2$ (whose utility value is 2.74 ).

Since different attributes have different weights, an insurance provider will concentrate on those factors where the weights are higher. So an insurance provider will be interested in improving on BOD than SS. 
Table 6: Comparisons of Existing Products

\begin{tabular}{|c|c|c|c|c|c|c|c|c|c|c|}
\hline Name & LP & FPS & TB & BOD & B0S & GCS & BN & SS & RID & SCORE \\
\hline $\begin{array}{c}\text { Weights } \\
\rightarrow\end{array}$ & 0.1141 & .01059 & 0.1362 & 0.1319 & 0.1211 & 0.1014 & 0.0978 & 0.0856 & 0.1059 & \\
\hline P1 & 4 & 5 & 3 & 4 & 4 & 5 & 3 & 4 & 5 & 4.07 \\
\hline P6 & 3 & 4 & 3 & 4 & 4 & 4 & 4 & 5 & 4 & 3.83 \\
\hline P3 & 3 & 4 & 3 & 3 & 3 & 4 & 3 & 5 & 3 & 3.37 \\
\hline P5 & 3 & 4 & 3 & 4 & 3 & 3 & 4 & 3 & 2 & 3.22 \\
\hline P4 & 5 & 3 & 4 & 2 & 3 & 2 & 3 & 4 & 3 & 3.21 \\
\hline P2 & 3 & 3 & 3 & 2 & 2 & 4 & 3 & 3 & 2 & 2.74 \\
\hline
\end{tabular}

Assuming that there are only these six insurance products in the market, in Table 7, we calculate the utility score of each insurance product as assigned by the buyer,. We then use a multinomial logit model [McFadden (1980), Luce and Suppes (1965) and Luce (1959)]. The multinomial logit model then calculates the probability that a customer will buy one of the products.

Table 7: Results Using Multinomial Logit Model

\begin{tabular}{|c|c|c|c|}
\hline Product Name & SCORE(Ui) & EXP(Ui) & Prob(Pi) \\
\hline P1 & 4.07 & 58.556962 & 0.294268 \\
\hline P6 & 3.83 & 46.062538 & 0.231479 \\
\hline P3 & 3.37 & 29.078527 & 0.146129 \\
\hline P5 & 3.22 & 25.028120 & 0.125774 \\
\hline P4 & 3.21 & 24.779086 & 0.124523 \\
\hline P2 & 2.74 & 15.486900 & 0.077827 \\
\hline Total & & 198.992133 & 1 \\
\hline
\end{tabular}

\section{Conclusion and Extensions}

We have investigated the weights corresponding to the parameters used for selecting life insurance policies and vehicle insurance policies. Combining these weights with a linear utility function we have been able to develop a framework that can compare and rank the life insurance policies currently available.

We believe that our work makes it possible to identify the (relative) key parameters and design insurance policies accordingly. Further surveys on life insurance will allow weights to be determined for segments of the population. These segments may be based on salary class, or nature of employment. Once these weights are defined, and the utility function is drawn up, insurance companies can even tailor their products according to the relative importance of specific features of the policy. 
This work can be extended in three directions. The first extension of this work will be sector specific. We note that this work has been carried out in the life insurance sector in India. A similar extension can be done in vehicle insurance or in the health insurance sector. While the same linear additive model may be applicable, the number of attributes and the weights of each attribute may be different.

The linear additive model can also be extended to the context of Revenue Management. As Revenue Management is an emerging research and application area, one of the important considerations from the point of the service provider is the utility of a customer. We believe no research work has been done in the Indian context and the logarithmic goal-programming model may be applicable in this context as well.

The second extension is based on the assumption of linearity. We have assumed the utility function to be linear. This may be a good approximation for the development of the utility function. However, in reality, the utility function may be non-linear. In such cases, it may be possible to find the second and higher order terms for each attribute in the model. The real challenge of this problem will be to collect data through market surveys for computing the higher order terms.

While we have shown that LGPM is a method to develop a linear utility function for the insurance method, it does not show how this method compares with that of conjoint analysis. A comparative study will be an interesting extension of this paper which we plan to take up in future. 


\section{References}

Aczel, J. and Satty, T. (1983). Procedures for Synthesizing Ration Judgments. Journal of Mathematical Psychology, 27, 93-102.

Basu, S., Dutta, G., Gupta, R. and Bhatnagar, A. (2004). Usage of Mathematical Models and Operation Research Techniques in The Insurance Industry. Journal of Insurance and Risk Management, Volume 3, No. 5, pp. 77-96.

Bessis, J. (2002). Risk Management in Banking. John Wiley \& Sons Ltd, UK

Bryson, N. \& Joseph, A. (1999). Generating Consensus Priority Point Vectors. Computers and Operations Research, 26, 637-643.

Cochrane, J. L. and Zeleny, M. (1973). Multiple Criteria Decision Making. University of South Carolina Press, USA.

Das, S. and Basu, S. (2003). A Markov Chain based N-Claims Discount System. Journal of Insurance \& Risk Management, 2/3, $61-72$.

Das, S. (2003). Joint Life Insurance Policies with differential benefits and premiums to the policyholders. Indian Institute of Management Bangalore Working paper No. 208.

Fourer R., Gay D.M., and Kernighan B.W, (1993). “AMPL (A Modeling Language for Mathematical Programming)",The Scientific Press Series, Boyd \& Fraser Publishing Company, CA 94080, USA.

Luce, R and Suppes, P, (1965). Preference Utility and Subjective Probability, Handbook of Mathematical Psychology, Volume 3, ed. By R. Luce et al., New York Wiley, pp. 249-441.

Luce R, (1959). Individual Choice Behaviour: A Theoretical Analysis, New York Wiley.

Markowitz H.M. (1952). Portfolio Selection, Journal of Finance, Volume 7, pp 77-91.

McFadden, D, (1980). Econometric Models for Probabilistic Choice among Products, Journal of Business, Volume 53, No 3, Part 2. pp. S13 - S29. 
Overview of Insurance Sector (2007): Retrieved from the web-site www.indiacore.com/insurance.html on April 26, 2004.

Satty T. L. (1980). The Analytic Hierarchical Process, New York, McGraw Hill Book Company.

Srinivasan, V. and Green, P. E. (1978). Conjoint Analysis in Consumer Research: Issues and Outlook, Journal of Consumer Research, Vol. 5, No. 2 pp. 103-123.

Srinivasan, V, (1980). Comments on Conjoint Analysis and Quantal Choice Models, Journal of Business, Vol. 53, No. 3, Part 2, pp. S45-S46.

Srinivasan, V. and Jain, A.K. and Malhotra, N. K., (1983). Improving Predictive Power of Conjoint Analysis by Constrained Parameter Estimation, Journal of Marketing Research, Vol. 20, No. 4, pp. 433-438.

Srinivasan, V. and Green, P. E. (1990). Conjoint Analysis in Marketing: New Developments with Implications for Research and Practice," Journal of Marketing, Vol. 54, No. 4, pp. 3-19.

Srinivasan, V. (1998). A Strict Paired Comparison Linear Programming Approach to Nonmetric Conjoint Analysis," in Operations Research: Methods, Models and Applications, ed. by J. E. Aronson and S. Zionts, Quorum Books, Wesport, Connecticut, USA, pp. 97-112. 


\section{Appendix - 1}

\section{Model explanation with a sample dataset}

In this part we explain the method using a small sample. We assume that there are eight factors and the maximum rating a respondent can assign, say, is 100 , and the minimum, say, is 1 .

Table 8: Sample data set

\begin{tabular}{|c|c|c|c|c|c|c|c|c|}
\hline Respondent & Factor & Factor & Factor & Factor & Factor & Factor & Factor & Factor \\
& $\mathbf{2}$ & $\mathbf{2}$ & $\mathbf{4}$ & $\mathbf{5}$ & $\mathbf{6}$ & $\mathbf{7}$ & $\mathbf{8}$ \\
\hline R 1 & 85 & 90 & 100 & 100 & 95 & 100 & 70 & 75 \\
\hline R 2 & 90 & 80 & 80 & 95 & 75 & 100 & 70 & 83 \\
\hline R 3 & 100 & 50 & 90 & 100 & 100 & 90 & 50 & 63 \\
\hline R 4 & 80 & 90 & 99 & 75 & 99 & 95 & 95 & 70 \\
\hline R 5 & 95 & 90 & 95 & 98 & 92 & 80 & 82 & 75 \\
\hline R 6 & 100 & 100 & 60 & 50 & 80 & 90 & 90 & 100 \\
\hline R 7 & 100 & 90 & 80 & 90 & 80 & 60 & 80 & 100 \\
\hline R 8 & 80 & 80 & 60 & 60 & 80 & 100 & 80 & 60 \\
\hline R 9 & 80 & 90 & 60 & 70 & 90 & 50 & 70 & 60 \\
\hline R 10 & 100 & 80 & 100 & 100 & 70 & 80 & 80 & 60 \\
\hline
\end{tabular}

Table 8 shows the sample data set. The first responder's score for the factors are 85, 90, 100, 100, 95, 100,70 and 75 respectively. Hence the values of responder $1(t=1)$ for attribute 1 and 2 (or $i=1$ and $j$ $=2)$ is $\mathrm{a}^{1}{ }_{12}=85 / 90=0.944$. Similarly, we can find that for responder $8, \mathrm{a}^{8}{ }_{23}=80 / 60=1.333$.

Based on the above mentioned method, we compute the $\mathrm{a}^{\mathrm{t}}{ }_{\mathrm{ij}}$ matrix. We show part of the matrix in Table 9

Table 9: Part computation of the $\mathbf{a}_{\mathrm{ij}}^{\mathrm{t}}$ matrix of sample data

\begin{tabular}{|c|c|c|c|c|c|c|c|}
\hline Respondent & a12 & a13 & a14 & a15 & a16 & a17 & a18 \\
\hline R 1 & 0.944 & 0.850 & 0.850 & 0.895 & 0.850 & 1.214 & 1.133 \\
\hline R 2 & 1.125 & 1.125 & 0.947 & 1.200 & 0.900 & 1.286 & 1.084 \\
\hline R 3 & 2.000 & 1.111 & 1.000 & 1.000 & 1.111 & 2.000 & 1.587 \\
\hline R 4 & 0.889 & 0.808 & 1.067 & 0.808 & 0.842 & 0.842 & 1.143 \\
\hline R 5 & 1.056 & 1.000 & 0.969 & 1.033 & 1.188 & 1.159 & 1.267 \\
\hline R 6 & 1.000 & 1.667 & 2.000 & 1.250 & 1.111 & 1.111 & 1.000 \\
\hline R 7 & 1.111 & 1.250 & 1.111 & 1.250 & 1.667 & 1.250 & 1.000 \\
\hline R 8 & 1.000 & 1.333 & 1.333 & 1.000 & 0.800 & 1.000 & 1.333 \\
\hline R 9 & 0.889 & 1.333 & 1.143 & 0.889 & 1.600 & 1.143 & 1.333 \\
\hline R 10 & 1.250 & 1.000 & 1.000 & 1.429 & 1.250 & 1.250 & 1.667 \\
\hline
\end{tabular}


Then we again implement equations 3 and 5 by making the transformation and putting it up in the matrix equation. We take the optimal values of $\mathrm{w}_{\mathrm{i}}$ and $\mathrm{V}_{\mathrm{i}}$ from the Excel solver, and after putting those values, we compute the values.

Table 10: Part computation of the $a_{i j}^{t}{ }^{t}\left(v_{i} / v_{j}\right)$ matrix of sample data

\begin{tabular}{|c|c|c|c|c|c|c|c|}
\hline Respondent & a12 & a13 & a14 & a15 & a16 & a17 & a18 \\
\hline R 1 & 0.894 & 0.805 & 0.815 & 0.847 & 0.774 & 1.048 & 0.895 \\
\hline R 2 & 1.065 & 1.065 & 0.909 & 1.137 & 0.819 & 1.110 & 0.856 \\
\hline R 3 & 1.894 & 1.052 & 0.959 & 0.947 & 1.011 & 1.726 & 1.253 \\
\hline R 4 & 0.842 & 0.765 & 1.023 & 0.765 & 0.766 & 0.727 & 0.902 \\
\hline R 5 & 1.000 & 0.947 & 0.930 & 0.978 & 1.081 & 1.000 & 1.000 \\
\hline R 6 & 0.947 & 1.578 & 1.918 & 1.184 & 1.011 & 0.959 & 0.789 \\
\hline R 7 & 1.052 & 1.184 & 1.066 & 1.184 & 1.517 & 1.079 & 0.789 \\
\hline R 8 & 0.947 & 1.263 & 1.279 & 0.947 & 0.728 & 0.863 & 1.053 \\
\hline R 9 & 0.842 & 1.263 & 1.096 & 0.842 & 1.456 & 0.986 & 1.053 \\
\hline R 10 & 1.184 & 0.947 & 0.959 & 1.353 & 1.138 & 1.079 & 1.316 \\
\hline
\end{tabular}

In the next table, we show the $\mathrm{p}_{\mathrm{ij}}^{\mathrm{t}}$ matrix by taking care of the fact

- if $\left(\mathrm{v}_{\mathrm{i}} / \mathrm{v}_{\mathrm{j}}\right)^{*} \mathrm{a}_{\mathrm{ij}}^{\mathrm{t}}>1$, then $\quad \mathrm{p}_{\mathrm{ij}}^{\mathrm{t}}=\mathrm{a}_{\mathrm{ij}}^{\mathrm{t}} \mathrm{*}\left(\mathrm{v}_{\mathrm{i}} / \mathrm{v}_{\mathrm{j}}\right)$, else $\mathrm{p}_{\mathrm{ij}}^{\mathrm{t}}=1$

We show $\mathrm{p}_{\mathrm{ij}}^{\mathrm{t}}$ matrix in Table 11

Table 11: Part computation of the $\mathbf{p}_{\mathrm{ij}}^{\mathrm{t}}$ matrix

\begin{tabular}{|c|c|c|c|c|c|c|c|}
\hline R 1 & 1.000 & 1.000 & 1.000 & 1.000 & 1.000 & 1.048 & 1.000 \\
\hline R 2 & 1.065 & 1.065 & 1.000 & 1.137 & 1.000 & 1.110 & 1.000 \\
\hline R 3 & 1.894 & 1.052 & 1.000 & 1.000 & 1.011 & 1.726 & 1.253 \\
\hline R 4 & 1.000 & 1.000 & 1.023 & 1.000 & 1.000 & 1.000 & 1.000 \\
\hline R 5 & 1.000 & 1.000 & 1.000 & 1.000 & 1.081 & 1.000 & 1.000 \\
\hline R 6 & 1.000 & 1.578 & 1.918 & 1.184 & 1.011 & 1.000 & 1.000 \\
\hline R 7 & 1.052 & 1.184 & 1.066 & 1.184 & 1.517 & 1.079 & 1.000 \\
\hline R 8 & 1.000 & 1.263 & 1.279 & 1.000 & 1.000 & 1.000 & 1.053 \\
\hline R 9 & 1.000 & 1.263 & 1.096 & 1.000 & 1.456 & 1.000 & 1.053 \\
\hline R 10 & 1.184 & 1.000 & 1.000 & 1.353 & 1.138 & 1.079 & 1.316 \\
\hline
\end{tabular}

We do similar transformation from $\mathrm{q}_{\mathrm{ij}}^{\mathrm{t}}$ Matrix and then we can compute the logarithmic values to get the objective function and the constraints

We now show the optimal solution of the model with the normalized values in table 12

Table 12: Optimal solution that has been used in the computation

\begin{tabular}{|c|c|c|c|c|c|c|c|}
\hline $\mathbf{1}$ & $\mathbf{2}$ & $\mathbf{3}$ & $\mathbf{4}$ & $\mathbf{5}$ & $\mathbf{6}$ & $\mathbf{7}$ & $\mathbf{8}$ \\
\hline 0.135814 & 0.12863 & 0.12863 & 0.130273 & 0.12863 & 0.1236 & 0.117213 & 0.10721 \\
\hline & & & & & & & \\
\hline
\end{tabular}




\section{Appendix -2}

\section{Life Insurance Study Questionnaire}

\section{Dear Sir/Madam}

We are participants at the MBA program of Indian Institute of Management, Ahmedabad (IIMA). We would like to know the factors you would consider when choosing a life insurance policy. Filling this questionnaire should not take you more than 3 minutes.

Thank you

Your Name:

Your Date of Birth:

Your Occupation (tick one):

Your Monthly Household Income (tick one):

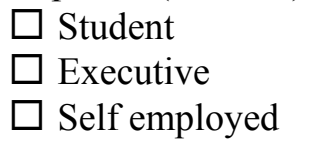

$$
\begin{aligned}
& \square<10000 \\
& \square 10000-20000 \\
& \square 20000-30000 \\
& \square 30000-40000 \\
& \square 40000-50000 \\
& \square 50000 \text { and above }
\end{aligned}
$$

Following are some factors people consider while buying an insurance policy. Indicate the importance of each factor in influencing your decision to buy a particular life insurance policy. Indicate the importance on a scale of 1 (not at all important) to 9 (very highly important)

\begin{tabular}{|c|l|l|}
\hline Serial No & Attribute Name & Relative Importance (1-9) \\
\hline 1 & Low premium & \\
\hline 2 & Flexibility in payment structure & \\
\hline 3 & Tax benefits in insurance plan & \\
\hline 4 & Benefits on death & \\
\hline 5 & Benefits on survival & \\
\hline 6 & $\begin{array}{l}\text { Good Customer Service } \\
\bullet \quad \text { Online Payment }\end{array}$ & \\
\hline 7 & $\begin{array}{l}\text { Bonus Renegotiation of term/insured amount } \\
\text { Add-ons, Special Schemes }\end{array}$ & \\
\hline 8 & $\begin{array}{l}\text { Loan against Policy } \\
\text { Group Schemes }\end{array}$ & \\
\hline 9 & $\begin{array}{l}\text { Availability of Riders enabling customization of } \\
\text { insurance plan }\end{array}$ & \\
& $\begin{array}{l}\text { C Critical illness benefit } \\
\text { Major surgical assistance }\end{array}$ & \\
\hline
\end{tabular}

